\title{
STOCHASTIC LEONTIEFF TYPE EQUATIONS IN TERMS OF CURRENT VELOCITIES OF THE SOLUTION II
}

\author{
Yu.E. Gliklikh, Voronezh State University, Voronezh, Russian Federation, \\ yeg@math.vsu.ru, \\ E. Yu. Mashkov, South-West State University, Kursk, Russian Federation, \\ mashkovevgen@yandex.ru
}

In papers by A.L. Shestakov and G.A. Sviridyuk a new model of the description of dynamically distorted signals in some radio devices is suggested in terms of so-called Leontieff type equations (a particular case of algebraic-differential equations). In that model the influence of noise is taken into account in terms of the so-called symmetric mean derivatives of the Wiener process instead of using white noise. This allows the authors to avoid using the generalized function. It should be pointed out that by physical meaning, the current velocity is a direct analog of physical velocity for the deterministic processes. Note that the use of current velocity of the Wiener process means that in the construction of mean derivatives the $\sigma$-algebra "present" for the Wiener process is under consideration while there is also another possibility: to deal with the $\sigma$-algebra "present" of the solution as it is usually done in the theory of stochastic differential equation with mean derivatives. This approach was previously suggested by the authors under the assumption that the matrix pencil, that determines the equation, satisfies the so-called "rank-degree" condition. In this paper we consider stochastic Leontieff type equation given in terms of current velocities of the solution without this assumption.

Keywords: mean derivatives; current velocities; stochastic Leontieff type equations.

\section{Introduction}

We understand the differential equations of Leontieff type as a special class of algebraicdifferential systems in $\mathbb{R}^{n}$ of the form

$$
L \dot{x}(t)=M x(t)+f(t),
$$

where $x(t)$ and $f(t)$ are $n$-dimensional vectors, $L$ and $M$ are constant $n \times n$ matrices where $L$ is degenerate and $M$ is not degenerate. With the use of such equations in papers by A.L. Shestakov and G.A. Sviridyuk (see e.g. $[1,2]$ ) the dynamical distortion of signals in radio devises is described. In the papers by L.A. Vlasenko T. Sickenberger and R. Winkler A.G Rutkas, M.S. Filipkovskaya and others such equations arise in mathematical models of oscillations and electric nets.

For applications of the above mentioned models it is important to take into account noise in the right-hand side of the Leontieff type equation, i.e., random perturbation of white noise type. Recall that the white noise is well-posed in the space of generalized functions. In papers [3-5] a new approach for investigation of Leontieff type equations with noise is suggested that replaces the white noise by Nelson's symmetric mean derivative (current velocity, see e.g. [7-9]) of the Wiener process that allows one to avoid using the generalised functions. The current velocities are natural analogues of usual physical velocities of deterministic processes. In this paper we investigate the processes that are 
described by Leontieff type equations in terms of the current velocities of the solutions. In should be pointed out that in such setting the current velocities of Wiener process are not involved from the very beginning.

The Leontieff type differential equations in terms of current velocity of solution are introduced and investigated in [6] under the additional assumption that the pencil of constant matrices satisfies the so-called "rank-degree" condition. Here we deal with the systems that do not satisfy this condition.

For simplicity we consider equations, their solutions and other objects on a finite time interval $t \in[0, T]$.

Everywhere in the text we use Einstein's summation convention in repeated upper and lower index.

\section{Preliminaries on the Mean Derivatives}

Consider a stochastic process $\xi(t)$ in $\mathbb{R}^{n}, t \in[0, l]$, given on a certain probability space $(\Omega, \mathcal{F}, \mathrm{P})$ and such that $\xi(t)$ is $L_{1}$-random variable for all $t$.

Every stochastic process $\xi(t)$ in $\mathbb{R}^{n}, t \in[0, l]$, determines three families of $\sigma$-subalgebras of $\sigma$-algebra $\mathcal{F}$ :

(i) the "past" $\mathcal{P}_{t}^{\xi}$ generated by pre-images of Borel sets in $\mathbb{R}^{n}$ by all mappings $\xi(s): \Omega \rightarrow \mathbb{R}^{n}$ for $0 \leq s \leq t$;

(ii) the "future" $\mathcal{F}_{t}^{\xi}$ generated by pre-images of Borel sets in $\mathbb{R}^{n}$ by all mappings $\xi(s)$ : $\Omega \rightarrow \mathbb{R}^{n}$ for $t \leq s \leq l$;

(iii) the "present" ("now") $\mathcal{N}_{t}^{\xi}$ generated by pre-images of Borel sets in $\mathbb{R}^{n}$ by the mapping $\xi(t)$.

All families are supposed to be complete, i.e., containing all sets of probability 0.

For convenience we denote the conditional expectation of $\xi(t)$ with respect to $\mathcal{N}_{t}^{\xi}$ by $E_{t}^{\xi}(\cdot)$

Ordinary ("unconditional") expectation is denoted by $E$.

Strictly speaking, almost surely (a.s.) the sample paths of $\xi(t)$ are not differentiable for almost all $t$. Thus its "classical" derivatives exist only in the sense of generalized functions. To avoid using the generalized functions, following Nelson (see, e.g., [7-9]) we give

Definition 1. (i) Forward mean derivative $D \xi(t)$ of $\xi(t)$ at time $t$ is an $L_{1}$-random variable of the form

$$
D \xi(t)=\lim _{\Delta t \rightarrow+0} E_{t}^{\xi}\left(\frac{\xi(t+\Delta t)-\xi(t)}{\Delta t}\right)
$$

where the limit is supposed to exists in $L_{1}(\Omega, \mathcal{F}, \mathrm{P})$ and $\Delta t \rightarrow+0$ means that $\Delta t$ tends to 0 and $\Delta t>0$.

(ii) Backward mean derivative $D_{*} \xi(t)$ of $\xi(t)$ at $t$ is an $L_{1}$-random variable

$$
D_{*} \xi(t)=\lim _{\Delta t \rightarrow+0} E_{t}^{\xi}\left(\frac{\xi(t)-\xi(t-\Delta t)}{\Delta t}\right)
$$

where the conditions and the notation are the same as in (i).

Note that mainly $D \xi(t) \neq D_{*} \xi(t)$, but if, say, $\xi(t)$ a.s. has smooth sample paths, these derivatives evidently coinside. 
From the properties of conditional expectation (see [10]) it follows that $D \xi(t)$ and $D_{*} \xi(t)$ can be represented as compositions of $\xi(t)$ and Borel measurable vector fields (regressions)

$$
\begin{aligned}
& Y^{0}(t, x)=\lim _{\Delta t \rightarrow+0} E\left(\frac{\xi(t+\Delta t)-\xi(t)}{\Delta t} \mid \xi(t)=x\right), \\
& Y_{*}^{0}(t, x)=\lim _{\Delta t \rightarrow+0} E\left(\frac{\xi(t)-\xi(t-\Delta t)}{\Delta t} \mid \xi(t)=x\right)
\end{aligned}
$$

on $\mathbb{R}^{n}$. This means that $D \xi(t)=Y^{0}(t, \xi(t))$ and $D_{*} \xi(t)=Y_{*}^{0}(t, \xi(t))$.

Definition 2. The derivative $D_{S}=\frac{1}{2}\left(D+D_{*}\right)$ is called symmetric mean derivative. The derivative $D_{A}=\frac{1}{2}\left(D-D_{*}\right)$ is called anti-symmetric mean derivative.

Consider the vector fields

$$
v^{\xi}(t, x)=\frac{1}{2}\left(Y^{0}(t, x)+Y_{*}^{0}(t, x)\right)
$$

and

$$
u^{\xi}(t, x)=\frac{1}{2}\left(Y^{0}(t, x)-Y_{*}^{0}(t, x)\right) .
$$

Definition 3. $v^{\xi}(t)=v^{\xi}(t, \xi(t))=D_{S} \xi(t)$ is called current velocity of $\xi(t)$; $u^{\xi}(t)=u^{\xi}(t, \xi(t))=D_{A} \xi(t)$ is called osmotic velocity of $\xi(t)$.

For stochastic processes the current velocity is a direct analogue of ordinary physical velocity of deterministic processes (see, e.g., [7-9,11]). The osmotic velocity measures how fast the "randomness" grows up.

Recall that Ito process is a process $\xi(t)$ of the form

$$
\xi(t)=\xi_{0}+\int_{0}^{t} a(s) d s+\int_{0}^{t} A(s) d w(s),
$$

where $a(t)$ is a process in $\mathbb{R}^{n}$ whose sample paths a.s. have bounded variation; $A(t)$ is a process in $L\left(\mathbb{R}^{n}, \mathbb{R}^{n}\right)$ such that for any element $A_{i}^{j}(t)$ of matrix $A(t)$ the condition $\mathrm{P}\left(\omega \mid \int_{0}^{T}\left(A_{i}^{j}\right)^{2} d t<\infty\right)=1$ holds; $w(t)$ is a Wiener process in $\mathbb{R}^{n}$; the first integral is Lebesgue integral, the second one is Itô integral and all integrals are well-posed.

Definition 4. An Itô process $\xi(t)$ is called a process of diffusion type if a $(t)$ and $A(t)$ are not anticipating with respect to $\mathcal{P}_{t}^{\xi}$ and the Wiener process $w(t)$ is adapted to $\mathcal{P}_{t}^{\xi}$. If $a(t)=a(t, \xi(t))$ and $A(t)=A(t, \xi(t))$, where $a(t, x)$ and $A(t, x)$ are Borel measurable mappings from $[0, T] \times \mathbb{R}^{n}$ to $\mathbb{R}^{n}$ and to $L\left(\mathbb{R}^{n}, \mathbb{R}^{n}\right)$, respectively, the Itô process is called a diffusion process.

Below we are dealing with smooth fields of non-degenerate linear operators $A(x)$ : $\mathbb{R}^{n} \rightarrow \mathbb{R}^{n}, x \in \mathbb{R}^{n}$ (i.e., $(1,1)$-tensor field on $\mathbb{R}^{n}$ ). Let $\xi(t)$ be a diffusion process in which the integrand under Itô integral is of the form $A(\xi(t))$. Then its diffusion coefficient $A(x) A^{*}(x)$ is a smooth field of symmetric positive definite matrices $\alpha(x)=\left(\alpha^{i j}(x)\right)((2,0)$ tensor field on $\left.\mathbb{R}^{n}\right)$. Since all these matrices are non-degenerate and smooth, there exist the smooth field of converse symmetric and positive definite matrices $\left(\alpha_{i j}\right)$. Hence this 
field can be used as a new Riemannian $\alpha(\cdot, \cdot)=\alpha_{i j} d x^{i} \otimes d x^{j}$ on $\mathbb{R}^{n}$. The volume form of this metric has the form $\Lambda_{\alpha}=\sqrt{\operatorname{det}\left(\alpha_{i j}\right)} d x^{1} \wedge d x^{2} \wedge \cdots \wedge d x^{n}$.

Remark 1. Below we deal with constant matrices $A$ and $\alpha$. Please note that in this case the field $\alpha(\cdot, \cdot)$ becomes a new Euclidean metric (inner product) on $\mathbb{R}^{n}$.

Denote by $\rho^{\xi}(t, x)$ the probability density of random element $\xi(t)$ with respect to the volume form $d t \wedge \Lambda_{\alpha}=\sqrt{\operatorname{det}\left(\alpha_{i j}\right)} d t \wedge d x^{1} \wedge d x^{2} \wedge \cdots \wedge d x^{n}$ on $[0, T] \times \mathbb{R}^{n}$, i.e., for every continuous bounded function $f:[0, T] \times \mathbb{R}^{n} \rightarrow \mathbb{R}$ the relation

$$
\int_{0}^{T} E(f(t, \xi(t))) d t=\int_{0}^{T}\left(\int_{\Omega} f(t, \xi(t)) d \mathrm{P}\right) d t=\int_{[0, T]}\left(\int_{\mathbb{R}^{n}} f(t, x) \rho^{\xi}(t, x) \Lambda_{\alpha}\right) d t
$$

holds.

Lemma 1. $[5,12]$ Let $\xi(t)$ satisfy the Ito equation

$$
\xi(t)=\xi_{0}+\int_{0}^{t} a(s, \xi(s)) d s+\int_{0}^{t} A(s, \xi(s)) d w(s) .
$$

Then

$$
u^{\xi}(t, x)=\frac{1}{2} \frac{\frac{\partial}{\partial x^{j}}\left(\alpha^{i j} \rho^{\xi}(t, x)\right)}{\rho^{\xi}(t, x)} \frac{\partial}{\partial x^{i}}
$$

where $\left(\alpha^{i j}\right)$ is the matrix of operator $A A^{*}$.

Corollary 1. If $A$ (and so also the matrix $\left(\alpha^{i j}\right)$ ) is constant and non-degenerate,

$$
u=\frac{1}{2} \alpha^{i j} \frac{\partial}{\partial x^{j}} \log \rho^{\xi}(t . x) \frac{\partial}{\partial x^{i}}=\frac{1}{2} \operatorname{Grad} \log \rho^{\xi}(t . x)
$$

where Grad is the gradient with respect to the inner product $\alpha(\cdot, \cdot)$.

Note that (5) is valid in the case where $A$ and so $\left(\alpha^{i j}\right)$ may be degenerate. If $A$ and so $\left(\alpha^{i j}\right)$ are not degenerate, the following proposition takes place.

Lemma 2. [9, 11]] Let the matrices $\left(\alpha^{i j}\right)$ be non-degenerate. For $v^{\xi}(t, x)$ and $\rho^{\xi}(t, x)$ the following interrelation

$$
\frac{\partial \rho^{\xi}(t, x)}{\partial t}=-\operatorname{Div}\left(v^{\xi}(t, x) \rho^{\xi}(t, x)\right)
$$

(known as the equation of continuity) takes place where Div denotes the divergence with respect to Riemannian metric $\alpha(\cdot, \cdot)$.

Following $[11,13]$ we introduce the differential operator $D_{2}$ that differentiates an $L_{1}$ random process $\xi(t), t \in[0, T]$ according to the rule

$$
D_{2} \xi(t)=\lim _{\triangle t \rightarrow+0} E_{t}^{\xi}\left(\frac{(\xi(t+\triangle t)-\xi(t))(\xi(t+\Delta t)-\xi(t))^{*}}{\triangle t}\right),
$$

where $(\xi(t+\triangle t)-\xi(t))$ is considered as a column vector (vector in $\left.\mathbb{R}^{n}\right),(\xi(t+\triangle t)-\xi(t))^{*}$ is a row vector (transposed, or conjugate vector) and the limit is supposed to exists in 
$L_{1}(\Omega, \mathcal{F}, \mathrm{P})$. We emphasize that the matrix product of a column on the left and a row on the right is a matrix so that $D_{2} \xi(t)$ is a symmetric positive semi-definite matrix function on $[0, T] \times \mathbb{R}^{n}$. We call $D_{2}$ the quadratic mean derivative.

Theorem 1. [11,13] For an Itô diffusion type process $\xi(t)$ as (4) the forward mean derivative $D \xi(t)$ exists and equals $E_{t}^{\xi}(a(t))$. In particular, if $\xi(t)$ a diffusion process, $D \xi(t)=a(t, \xi(t))$.

Theorem 2. [11,13] Let $\xi(t)$ be a diffusion type process as $(4)$. Then $D_{2} \xi(t)=E_{t}^{\xi}[\alpha(t)]$ where $\alpha(t)=A A^{*}$ is the diffusion coefficient. In particular, if $\xi(t)$ is a diffusion process, $D_{2} \xi(t)=\alpha(t, \xi(t))$ where $\alpha=A A^{*}$ is the diffusion coefficient.

Theorem 3. [11,13] Let $\alpha(t, x)$ be a jointly continuous (measurable, smooth) mapping from $[0, T] \times \mathbb{R}^{n}$ to $\mathrm{S}_{+}(n)$ (i.e., those matrices are non-degenerate). Then there exists a jointly continuous (measurable, smooth, respectively) mapping $A(t, x)$ from $[0, T] \times \mathbb{R}^{n}$ to $L\left(\mathbb{R}^{n}, \mathbb{R}^{n}\right)$ such that for all $t \in R, x \in \mathbb{R}^{n}$ the equality $A(t, x) A^{*}(t, x)=\alpha(t, x)$ holds.

\section{The Main Result}

We start this section with a glossary of some facts from matrix theory. Detailed explanation of this material can be found, e.g., in [14,15].

Definition 5. Let two $n \times n$ constant matrices $A$ and $B$ be given. The expression $\lambda A+B$ where $\lambda$ is a real or complex valued parameter, is called the matrix pencil. The polynomial $\operatorname{det}(\lambda A+B)$ (with respect to $\lambda$ ) is called the characteristic polynomial of the pencil. If $\operatorname{det}(\lambda A+B)$ is not identical zero, the pencil is called regular.

Theorem 4. Let the matrix pencil $\lambda A+B$ be regular. Then there exist non-degenerate matrices $P$ and $Q$ such that

$$
P(\lambda A+B) Q=\lambda\left(\begin{array}{cc}
I_{d} & 0 \\
0 & N
\end{array}\right)+\left(\begin{array}{cc}
J & 0 \\
0 & I_{n-d}
\end{array}\right)
$$

where $I_{d}$ and $I_{n-d}$ are unit matrices of the corresponding dimensions, $N$ is an upper triangle matrix consisting of Jordan boxes with zeros on diagonal and $J$ is a certain $d \times d$ block.

Let $\tilde{L}$ be a degenerate $n \times n$ matrix and $\tilde{M}$ be a non-degenerate $n \times n$ matrix such that the pencil $\lambda \tilde{L}+\tilde{M}$ is regular. Introduce a certain symmetric positive semi-definite $n \times n$ matrix $\Theta$ and consider the matrix $\bar{\Theta}=Q \Theta Q^{*}$. Evidently $\bar{\Theta}$ is symmetric and positive semi-definite.

For $C^{\infty}$-smooth vector-function $f(t)$ we consider the system

$$
\left\{\begin{array}{l}
\tilde{L} D_{S} \xi(t)=\tilde{M} \xi(t)+\tilde{f}(t) \\
D_{2} \xi(t)=\bar{\Theta}
\end{array}\right.
$$

that we call the stochastic Leontieff type equation with current velocities.

Take matrices $P$ and $Q$ from Theorem 4 and construct matrices $L=P \tilde{L} Q$ and $M=$ $P \tilde{M} Q$. From formula (9) it follows that

$$
L=\left(\begin{array}{cc}
I_{d} & 0 \\
0 & N
\end{array}\right) \text { and } M=\left(\begin{array}{cc}
J & 0 \\
0 & I_{n-d}
\end{array}\right) .
$$


Note that since $\tilde{M}$ is non-degenerate, $J$ is also non-degenerate.

Consider $\eta(t)=Q^{-1} \xi(t)$ and $f(t)=P \tilde{f}(t)$. Then according to the transformation of equation (10), explained in Theorem 4, we obtain the first line in (10) in the form $L D_{S} \eta(t)=M \eta(t)+f(t)$. Since $\eta(t)=Q^{-1} \xi(t)$, from the definition of $\Theta$ and definition of $D_{2}$ by formula (8) we get that the second line of (10) for $\eta(t)$ takes the form $D_{2} \eta(t)=\Theta$. Thus, equation (10) is transformed into the equation for $\eta(t)$ in the form

$$
\left\{\begin{array}{l}
L D_{S} \eta(t)=M \eta(t)+f(t) \\
D_{2} \eta(t)=\Theta .
\end{array}\right.
$$

Thus, taking into account formula (11), one can easily see that the first equation in (12) splits into two independent equations: $D_{S} \eta_{1}(t)=J \eta_{1}(t)+f_{1}(t)$ and $N D_{S} \eta_{2}(t)=$ $\eta_{2}(t)+f_{2}(t)$ where $\eta_{1}(t)$ and $f_{1}(t)$ are constructed from the first $d$ coordinates of vectors $\eta(t)$ and $f(t)$, respectively, and $\eta_{2}(t)$ and $f_{2}(t)$ are constructed from the last $n-d$ coordinates of $\eta(t)$ and $f(t)$, respectively. This means that (12) might be solvable only if the matrix $\Theta$ takes the form $\left(\begin{array}{cc}\alpha_{1} & 0 \\ 0 & \alpha_{2}\end{array}\right)$ where $\alpha_{1}=\left(\alpha_{1}^{i j}\right)$ is a symmetric positive semi-definite $d \times d$ matrix and $\alpha_{2}=\left(\alpha_{2}^{i j}\right)$ is a symmetric positive semi-definite $(n-d) \times(n-d)$ matrix.

Hence (12) splits into two independent systems:

$$
\left\{\begin{array}{l}
D_{S} \eta_{1}(t)=J \eta_{1}(t)+f_{1}(t) \\
D_{2} \eta_{1}(t)=\alpha_{1}
\end{array}\right.
$$

and

$$
\left\{\begin{array}{l}
N D_{S} \eta_{2}(t)=\eta_{2}(t)+f_{2}(t) \\
D_{2} \eta_{1}(t)=\alpha_{2}
\end{array}\right.
$$

Let us first consider (13). Suppose that the matrix $\alpha_{1}$ is non-degenerate (i.e., positive definite). For convenience we denote $C^{\infty}$-smooth vector field $J x+f_{(1)}(t)$ in $\mathbb{R}^{d}$ by $v(t, x)$ and denote its flow by $g_{t}$. Consider a probability density $\rho_{0}$ in $\mathbb{R}^{d}$ such that it nowhere equals zero. In this case it follows from [16, Theorem 3] that the density $\rho(t)$ of the solution to (13) with initial density $\rho_{0}$ takes the form $\rho(t)=e^{p(t)}$ where $p(t, x)=p_{0}\left(g_{-t}(x)\right)-$ $\int_{0}^{t}(\operatorname{Div} v)\left(s, g_{s}\left(g_{-t}(x)\right) d s, p_{0}=\ln \rho_{0}\right.$. Here Div denotes the divergence with respect to inner product $\alpha_{1}(\cdot, \cdot)$ (see Remark 1). Note that $\rho(t, x)$ is well-posed for all $t \in[0, T]$. By the construction $v$ is the current velocity of $\eta_{1}(t)$. Since the quadratic mean derivative is given as $\alpha_{1}$ and we have found the density $\rho$, we can also find the osmotic velocity $u$ by formula (6) and so the forward mean derivative $a=v+u$. Since $\alpha_{1}$ is non-degenerate, by Theorem 3 there exists a matrix $A$ such that $\alpha_{1}=A A^{*}$. Then $\eta_{1}$ must satisfy the following stochastyic differential equation in Ito form:

$$
\eta_{1}(t)=\eta_{1}(0)+\int_{0}^{t} a\left(s, \eta_{1}(s)\right) d s+\int_{0}^{t} A\left(s, \eta_{1}(s)\right) d w(s)
$$

in $\mathbb{R}^{d}$ where $\eta_{1}(0)$ is the random variable with density $\rho_{0}$. Equation (15) evidently has a strong and strongly unique solution well-posed on the entire interval $[0, T]$. .

Now let us turn to (14). Consider this equation on the example of $(p+1) \times(p+1)$ Jordan box in the upper left corner of $N$. In coordinates, equation (14) in this blok has 
the form:

$$
\left(\begin{array}{ccccc}
0 & 1 & 0 & \ldots & 0 \\
0 & 0 & 1 & \ldots & 0 \\
\vdots & \vdots & \vdots & \ldots & \vdots \\
0 & 0 & 0 & \ldots & 1 \\
0 & 0 & 0 & \ldots & 0
\end{array}\right) D_{S}\left(\begin{array}{c}
\eta_{2}^{d+1}(t) \\
\eta_{2}^{d+2}(t) \\
\vdots \\
\eta_{2}^{d+p}(t) \\
\eta_{2}^{d+p+1}(t)
\end{array}\right)=\left(\begin{array}{c}
\eta_{2}^{d+1}(t)+f_{2}^{d+1} \\
\eta_{2}^{d+2}(t)+f_{2}^{d+2} \\
\vdots \\
\eta_{2}^{d+p}(t)+f_{2}^{d+p} \\
\eta_{2}^{d+p+1}(t)+f_{2}^{d+p+1}
\end{array}\right)
$$

Thus $\eta_{2}^{d+p+1}(t)=-f_{2}^{d+1}$ and so $\eta_{2}^{d+p+1}(t)$ is not random. Note that for non-random processes $D_{S}$ coincides with $\frac{d}{d t}$. Then from the last but one line in (16) we see that $\eta_{2}^{d+p}(t)=\frac{d \eta_{2}^{d+p+1}(t)}{d t}-f_{2}^{d+p}=-\frac{d f_{2}^{d+p+1}(t)}{d t}-f_{2}^{d+p}$ and so $\eta_{2}^{d+p}(t)$ is not random either. Analogous arguments show that all other coordinates of $\eta_{2}(t)$ in (16) are not random. Note that (14) splits into independent equations corresponding to the Jordan boxes in $N$ and for all those equations the above arguments are valid. Hence the process $\eta_{2}(t)$ is not random. But for any non-random process its quadratic derivative is equal to zero. So, (14) is solvable only if $\alpha_{2}=0$.

Note in addition that since $\eta_{2}(t)$ is non-random, the "present" $\sigma$-algebra for $\eta(t)$ coincides with that for $\eta_{1}(t)$.

Thus we have proved the following statement:

Theorem 5. Let $\tilde{L}$ and $\tilde{M}$ be degenerate $(\operatorname{rank} \tilde{L}=d)$ and non-degenerate, respectively, $n \times n$-matrices, such that the pencil $\lambda \tilde{L}+\tilde{M}$ is regular; let $P$ an $Q$ be $n \times n$ matrices that transform the pencil $\lambda \tilde{L}+\tilde{M}$ into canonical form with $L=P \tilde{L} Q$ and $M=P \tilde{M} Q$; let $\alpha_{1}$ be a symmetric positive definite $d \times d$ matrix and $n \times n$ matrix $\Theta$ have the form $\Theta=$ $\left(\begin{array}{cc}\alpha_{1} & 0 \\ 0 & 0\end{array}\right)$. Then for every finite interval $[0, T]$ and for every $C^{\infty}$-smooth $n$-dimensional vector-function $f(t)$ equation (12) with initial conditions $\eta_{2}(0)=x_{0}$ in $R^{n-d}$ and $\eta_{1}(0)$ equal to a random variable with density $\rho_{0}$ nowhere equal to zero in $R^{d}$, has a solution that is well-posed on the entire interval $[0, T]$.

If $\eta(t)$ is the above-mentioned solution of $(12)$, the process $\xi(t)=Q \eta(t)$ is a solution of $(10)$.

Acknowledgements. The research is supported by Russian Science Foundation (RSF) Grant 14-21-00066, being carried out in Voronezh State University.

\section{References}

1. Shestakov A.L., Sviridyuk G.A. A New Approach to Measurement of Dynamically Distorted Signals. Bulletin of the South Ural State University. Series: Mathematical Modelling, Programming and Computer Software, 2010, no. 16 (192), pp. 116-120. (in Russian)

2. Shestakov A.L., Sviridyk G.A. Optimal Measurement of Dynamically Distorted Signals. Bulletin of the South Ural State University. Series: Mathematical Modelling, Programming and Computer Software, 2011, no. 17 (234), pp. 70-75. (in Russian)

3. Shestakov A.L., Sviridyk G.A. On the Measurement of the "White Noise". Bulletin of the South Ural State University. Series: Mathematical Modelling, Programming and Computer Software, 2012, no. 27 (286), pp. 99-108. 
4. Gliklikh Yu.E. Investigation of Leontieff Type Equations with White Noise by the Method of Mean Derivatives of Stochastic Processes. Bulletin of the South Ural State University. Series: Mathematical Modelling, Programming and Computer Software, 2012, no. 27 (286), pp. 24-34. (in Russian)

5. Gliklikh Yu.E., Mashkov E.Yu. Stochastic Leontieff Type Equations and Mean Derivatives of Stochastic Processes. Bulletin of the South Ural State University. Series: Mathematical Modelling, Programming and Computer Software, 2013, vol. 6, no. 2, pp. 25-39.

6. Gliklikh Yu.E., Mashkov E.Yu. Stochastic Leontieff Type Equations in Terms of Current Velocities of the Solution. Journal of Computational and Engineering Mathematics, 2014, vol. 1 , no. 2, pp. $45-51$.

7. Nelson E. Derivation of the Schrodinger Equation from Newtonian Mechanics. Physical Review, 1966, vol. 150, no. 4, pp. 1079-1085. DOI: 10.1103/PhysRev.150.1079

8. Nelson E. Dynamical Theory of Brownian Motion. Princeton, Princeton University Press, 1967.

9. Nelson E. Quantum Fluctuations. Princeton: Princeton University Press, 1985.

10. Parthasarathy K.R. Introduction to Probability and Measure. N.Y., Springer, 1978.

11. Gliklikh Yu.E. Global and Stochastic Analysis with Applications to Mathematical Physics. London, Springer, 2011. DOI: 10.1007/978-0-85729-163-9

12. Cresson J., Darses S. Stochastic Embedding of Dynamical Systems. Journal of Mathematical Physics, 2007, vol. 48, pp. 072703-1-072303-54.

13. Azarina S.V., Gliklikh Yu.E. Differential Inclusions with Mean Derivatives. Dynamic Systems and Applications, 2007, vol. 16, no. 1, pp. 49-71.

14. Chistyakov V.F., Shcheglova A.A. Selected Chapters of Differential Algebraic Equations Theory. Novosibirsk, Nauka, 2003. (in Russian)

15. Gantmacher F.R. The Theory of Matrices. N.Y., Chelsea Publishing Company, 1959.

16. Azarina S.V., Gliklikh Yu.E. On Existence of Solutions to Stochastic Differential Equations with Current Velocities. Bulletin of the South Ural State University. Series: Mathematical Modelling, Programming and Computer Software, 2015, vol. 8, no. 4, pp. 100-106. DOI: $10.14529 / \mathrm{mmp} 150408$

Received May 11, 2016

УДК $517.9+519.216 .2$

DOI: $10.14529 / \mathbf{m m p} 160303$

\section{СТОХАСТИЧЕСКИЕ УРАВНЕНИЯ ЛЕОНТЬЕВСКОГО ТИПА В ТЕРМИНАХ ТЕКУЩИХ СКОРОСТЕЙ РЕШЕНИЯ II}

Ю.Е. Гликлих, Е.Ю. Машков

В работах А.Л. Шестакова и Г.А. Свиридюка предложена новая модель описания динамически искаженных сигналов в некоторых радио устройствах на основе использования так называемых уравнений леонтьевского типа (частный случай 
дифференциально-алгебраических уравнений). В этих работах в этой модели были учтены помехи в терминах так называемых симметрических производных в среднем (текущих скоростей) винеровского процесса вместо использования белого шума. Это позволило авторам избежать использования обобщенных функций. Следует отметить, что по физическому смыслу текущих скоростей, они являются прямым аналогом физической скорости детерминированных процессов. Отметим, что использование текущих скоростей винеровского процесса означает, что в конструкции производных в среднем задействована $\sigma$-алгебра «настоящее» именно винеровского процесса, хотя имеется также другая возможность - использовать $\sigma$-алгебру «настоящее» решения, как это обычно делается в теории стохастических дифференциальных уравнений с производными в среднем. Такой подход был предложен ранее в работах авторов при дополнительном условии, что матричный пучок, определяющий уравнение, удовлетворяет так называемому условию «ранг-степень». В настоящей работе мы рассматриваем стохастические уравнения леонтьевского типа в терминах текущих скоростей решения без предположения о выполнении условия «ранг-степень».

Ключевые слова: производные в среднем; текущие скорости; стохастическое уравнение леонтвевского типа.

\section{Литература}

1. Шестаков, А.Л. Новый подход к измерению динамически искаженных сигналов / А.Л. Шестаков, Г.А. Свиридюк // Вестник ЮУрГУ. Серия: Математическое моделирование и программирование. - 2010. - № 16 (192), вып. 5. - С. 116-120.

2. Шестаков, А.Л. Оптимальное измерении динамически искаженных сигналов / А.Л. Шестаков, Г.А. Свиридюк // Вестник ЮУрГУ. Серия: Математическое моделирование и программирование. - 2011. - № 17 (234), вып. 8. - С. 70-75.

3. Шестаков, А.Л. Об измерении белого шума / А. Л. Шестаков, Г. А. Свиридюк // Вестник ЮУрГУ. Серия: Математическое моделирование и программирование. - 2012. № 27 (286), вып. 13. - С. 99-108.

4. Гликлих, Ю.Е. Изучение уравнений леонтьевского типа с белым шумом методами производных в среднем случайных процессов / Ю.Е. Гликлих // Вестник ЮУрГУ. Серия: Математическое моделирование и программирование. - 2012. - № 27 (286), вып. 13. C. $24-34$.

5. Gliklikh, Yu.E. Stochastic Leontieff Type Equations and Mean Derivatives of Stochastic Processes / Yu.E. Gliklikh, E.Yu. Mashkov // Вестник ЮУрГУ. Серия: Математическое моделирование и программирование. - 2013. - Т. 6, № 2 - С. 25-39.

6. Gliklikh, Yu.E. Stochastic Leontieff Type Equations in Terms of Current Velocities of the Solution / Yu.E. Gliklikh, E.Yu. Mashkov // Journal of Computational and Engineering Mathematics. - 2014. - V. 1, № 2. - P. 45-51.

7. Nelson, E. Derivation of the Schrodinger Equation from Newtonian Mechanics / E. Nelson // Physical Review. - 1966. - V. 150, № 4. - P. 1079-1085.

8. Nelson, E. Dynamical Theory of Brownian Motion / Nelson E. - Princeton: Princeton University Press. - 1967. - 114 p.

9. Nelson, E. Quantum Fluctuations / E. Nelson. - Princeton: Princeton University Press. 1985. - $146 \mathrm{p}$.

10. Партасарати, К. Введение в теорию вероятностей и теорию меры / К. Партасарати. М.: Мир. - 1988. - 343 с.

11. Gliklikh, Yu.E. Global and Stochastic Analysis with Applications to Mathematical Physics / Yu.E. Gliklikh. - London: Springer. - 2011. - 465 p. 
12. Cresson, J. Stochastic Embedding of Dynamical Systems / J. Cresson, S. Darses // Journal of Mathematical Physics. - 2007. - V. 48. - P. 072703-1-072303-54.

13. Azarina, S.V. Differential Inclusions with Mean Derivatives / S.V. Azarina, Yu.E. Gliklikh // Dynamic Systems and Applications. - 2007. - V. 16, № 1. - P. 49-71.

14. Чистяков, В.Ф. Избранные главы теории алгебро-дирфференциальных систем / В.Ф. Чистяков, А.А. Щеглова. - Новосибирск: Наука. - 2003. - 319 с.

15. Гантмахер, Ф.Р. Теория матриц / Ф.Р. Гантмахер. - М.: Физматлит. - 1967. - 575 с.

16. Azarina, S.V. On Existence of Solutions to Stochastic Differential Equations with Current Velocities / S.V. Azarina, Yu.E. Gliklikh // Вестник ЮУрГУ. Серия: Математическое моделирование и программирование. - 2015. - V. 8, № 4. - Р. 100-106.

Юрий Евгеньевич Гликлих, доктор физико-математических наук, профессор, кафедра алгебры и топологических методов анализа, Воронежский государственный университет (г. Воронеж, Российская федерация), уeg@math.vsu.ru.

Евгений Юрьевич Машков, кандидат физико-математических наук, кафедра высшей математики, Юго-Западный государственный университет, (г. Курск, Российская федерация), mashkovevgen@yandex.ru.

Поступила в редакиию 11 мая 2016 г. 